\title{
Incidence, Epidemiology and Etiology of Injuries, in a Spanish Amateur Football Club
}

\author{
Eduardo Esteban-Zubero, ${ }^{1, *}$ Paula Canabate-Valdeperez, ${ }^{2}$ Jaime Esteban-Perez, ${ }^{2}$ Maria \\ Sango-Martinez, and Silvia Castan-Ruiz ${ }^{3}$ \\ ${ }_{1}^{1}$ Department of Pharmacology and Physiology, University of Zaragoza, Zaragoza, Spain \\ ${ }_{3}^{2}$ Health Science Department, University of Zaragoza, Zaragoza, Spain \\ ${ }^{3}$ Primary Care Department, Hospital Clinico Universitario Lozano Blesa, Zaragoza, Spain \\ *Corresponding author: Eduardo Esteban-Zubero, Department of Pharmacology and Physiology, University of Zaragoza, Zaragoza, Spain. Tel: +34-654123994, E-mail: eezubero@gmail.com
}

Received 2015 August 19; Revised 2015 September 15; Accepted 2015 September 25.

\begin{abstract}
Background: Playing football, both at the amateur and professional level, associates an increased risk of injury. A documented report on injury location, type and incidence, in correlation with sports intensity, professionalism level and age, would be of support for implementing preventing measures and appropriate training programs, to reduce the incidence of football related injury.

Objectives: This study aimed to assess the incidence, type and location of injuries during one season, in an amateur football club and design strategies and preventive measures.

Patients and Methods: A population of 308 players were studied, aged between 5 and 29 years old (20 subjects over-19, 38 under-19, 38 under-16, 57 under-14, 57 under-12, 44 under-10 and 54 under-8 years old, respectively) distributed over 20 teams. In total, 339 cases of injury occurred.

Results: The population injured the most was the under-19 group and the most prevalent type of injuries was muscular (40.7\%) and ligament (16.5\%). The most common location was the lower limbs (78.6\%) and, specifically, the thigh (39.8\%). Physical load periods (September and February) were highlighted as the months of highest incidence and the average number of visits per injury was 1.34 . A statistically significant relationship between hours of training and injuries was noted.

Conclusions: In the literature, there are similar publications, who studied these variables, separately. This work provides us with a certain amount of descriptive results, which may serve as a model for future research projects, performing interventions by coaches and medical services of football clubs, to reduce the injuries incidence, especially in the months of greatest physical load and, therefore, improve the performance. Football is a safe sport to practice, at any age, because injuries, regularly, are not serious and it is highly recommended, given the amount of health benefits obtained.
\end{abstract}

Keywords: Athletic Injuries, Football, Thigh, Rehabilitation, Training/Conditioning, Injury

\section{Background}

Football is one of the most popular sports in Spain and, on the basis of federated members, has the highest level of participation. During the $2012-2013$ season, $96 \%$ of participants were male, while only $4 \%$ were female. The majority of these were of school age (80\%) or non-professional players (98\% of adult participants) (1).

Training and regular football playing have shown cardiovascular and musculoskeletal benefits $(2,3)$. However, as a physical contact sport, it associates injury risks. Due to the high level of participation, the prevalence of injuries in young players is ever increasing (3-5) and represents an important financial impact on public health services (6). For this reason, efforts are required to prevent and control these injuries, in particular those demonstrating a possible long-term nature $(6,7)$.

\section{Objectives}

The objective of our study was to evaluate the injury incidence, type and location, in players from an amateur club, which would enable the design and implementation of strategies and preventive measures, to reduce related collateral effects.

\section{Patients and Methods}

All families were sent a letter and information leaflet, inviting them to take part in the study. An informational meeting was organized to know the different organizers of the study. Informed written consent was obtained, from the main carer of each child, and children provided assent to their participation. Ethical approval for the study was granted by the ethics committee of the University of Zaragoza, Zaragoza, Spain.

Copyright (C) 2015, Iran University of Medical Sciences. This is an open-access article distributed under the terms of the Creative Commons Attribution-NonCommercial 4.0 International License (http://creativecommons.org/licenses/by-nc/4.0/) which permits copy and redistribute the material just in noncommercial usages, provided the original work is properly cited. 
During the period of one season of competition (9 months from September 2012 to May 2013), all cases of football-related injuries were selected from a total of 308 federated players, belonging to an amateur football club from Zaragoza, divided into categories: 20 adults $\geq 19$ years, 38 under-19, 38 under-16, 57 under-14, 57 under-12, 44 under-10, and 54 under-8 years old, respectively. During the period studied, 339 cases of injury were documented and duly recorded, in our database. All injuries resulting from training, official matches and friendlies were recorded. All non-football related injuries were excluded. The variables recorded were: team category (adults, under 19 , under-16, under-14, under-12, under-10, under-8), type of injury (muscular injury, tendon injury, ligament injury, contusions, other: meniscus, fractures, inflammation), location (thigh, knee, leg, foot, neck, shoulder, back, hand, other: chest, head, forearm etc.), treatment received [intramuscular treatment (empowerment, strengthening), inter-muscular treatment (massage, stretching, relaxation), thermotherapy, electrotherapy, articulate treatment (rescheduling and mobilization exercises), bandage/stabilizer, pharmacological), other], number of visits per case, month of injury and training hours (180 hours/per season for adults, under-19 and under-16;120 hours/per season forunder-14, under-12, under-10 and under-8).

A descriptive analysis of variables was carried out, followed by a bivariate analysis, using chi square or comparison of means and ANOVA, using statistical program SPSS version 15 (SPSS Inc. Chicago, IL, USA), establishing a level of significance of 95\%. Proportions were analyzed using the chi-square test, where appropriate. For data with small frequencies, a simple qualitative descriptive analysis was used. The average number of visits per injury, the average number of treatment received per injury and we the relationship between hours of training and the number of visits and treatments were analyzed, using factorial analysis of variance.

\section{Results}

A total of 339 injuries were recorded and divided into the following categories, per team. Adults $40.7 \%(\mathrm{n}=138)$, under-19 23\% $(\mathrm{n}=78)$, under-16 9.4\% $(\mathrm{n}=32)$, under-14 and under-12 9.7\% ( $n=33)$, under-10 4.7\% $(n=16)$ and under-8 $2.7 \%(n=9)$.

The month showing the highest number of injuries was February, with 55 events, followed by September, with 45, and by November, with 43. December had the smallest number of injuries, with 14events (Figure 1).

Regarding the type of injury, muscular injury was the most common (52.5\%), followed by ligament injury (16.5\%) and contusions (11.2\%).

Regarding location of injury, the most common was the thigh region, with 134 cases (39.8\%), foot-related, with 63 cases (18.6\%) and knee injuries, with 44 cases (13\%). The above locations, globally, in addition to injuries to the shin, demonstrate that $78.6 \%$ of all injuries were located in the lower limbs. The right side was the most affected
(50.7\%), followed by left side (37.2\%) and the smallest incidence was on both sides (6.4\%). The head and axial skeleton accounted for $5.7 \%$ of injuries. Table 1 details the etiology and location of injuries.

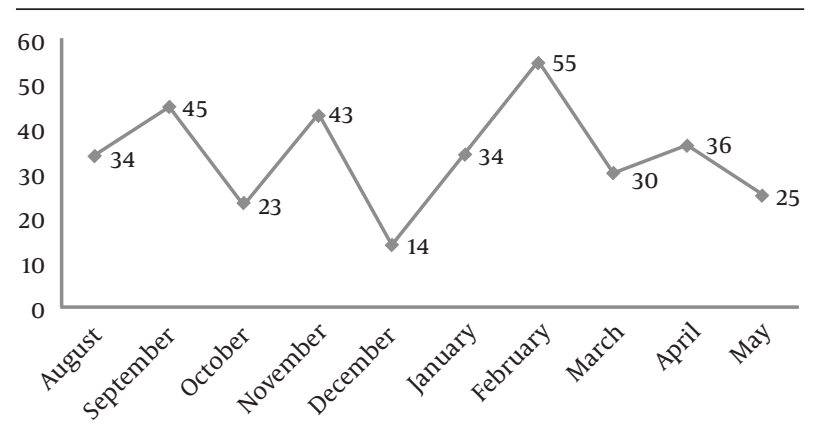

Figure 1. Number of Injuries per Month

Table 1. Etiology and Location of Injuries and Treatment Received $^{\mathrm{a}}$

\begin{tabular}{|c|c|}
\hline Injury Data & Total Injury Values \\
\hline \multicolumn{2}{|l|}{ Etiology of injury } \\
\hline Muscle injury & $178(52.5)$ \\
\hline Tendon injury & $26(7.7)$ \\
\hline Ligamentous injury & $56(16.5)$ \\
\hline Contusions & $38(11.2)$ \\
\hline Other & $41(12.1)$ \\
\hline \multicolumn{2}{|l|}{ Location of injury } \\
\hline Thigh & $134(39.8)$ \\
\hline Knee & $44(13.1)$ \\
\hline Leg & $24(7.1)$ \\
\hline Foot & $63(18.7)$ \\
\hline Neck & $14(4.2)$ \\
\hline Shoulder & $6(1.8)$ \\
\hline Back & $21(6.2)$ \\
\hline Hand & $17(5)$ \\
\hline Other & $14(4.2)$ \\
\hline \multicolumn{2}{|l|}{ Treatment received } \\
\hline Intramuscular treatment & $4(1.3)^{b}$ \\
\hline Intermuscular treatment & $151(44.8)^{\mathrm{C}}$ \\
\hline Thermotherapy & $82(24.3)^{\mathrm{d}}$ \\
\hline Electrotherapy & $26(7.5)^{\mathrm{e}}$ \\
\hline Articulate treatment & $24(7)^{\mathrm{f}}$ \\
\hline Bandage/stabilizer & $46(13.5)^{\mathrm{g}}$ \\
\hline Pharmacological & $2(0.7)$ \\
\hline Other & $2(0.7)$ \\
\hline
\end{tabular}

${ }^{\mathrm{a}}$ Data are presented as No. (\%).

$\mathrm{b}_{\text {Empowerment, strengthening. }}$

$\mathrm{c}_{\text {Massage, stretching, relaxation. }}$

$\mathrm{d}_{\text {Local cold and local heat. }}$

$\mathrm{e}_{\text {Ultrasonic treatment. }}$

$\mathrm{f}_{\text {Rescheduling and mobilization exercises. }}$

$\mathrm{g}_{\text {Functional bandage, kinesiotape, preventive bandage. }}$ 
The average number of visits per injury, to the medical services, was 1.34 (SD 0.83). In 79.7\% of cases, one single visit was sufficient to cure the problem, even though, in two cases of muscular injury, six visits were required.

The average number of treatment sessions, received per injury, was 2.41 (SD 1.31). Only $26.3 \%$ of cases required one single treatment, while $36.3 \%$ required two treatments. Two cases of muscular injury and one case of ligament injury required up to seven separate treatments.

Regarding treatment applied, almost $45 \%$ were muscular/intramuscular related, followed by thermotherapy (heat treatment) (24.3\%) and by bandaging/stabilizing (13.5\%) (Table 1).

When we compared the hours of training to the number of visits and treatments, we observed a statistically significant difference (significance level of 0.05), as well as in the relationship between team category, visits and the number of treatments $(\mathrm{P}<0.05)$. Additionally, we observed a relationship of statistical significance between the number of visits and the number of treatments (significance level of 0.001).

\section{Discussion}

Adult football players were the subgroup with the highest number of injuries and, in consequence, the subgroup requiring the highest level of healthcare, in comparison to others. This may be due, in general terms, to the probable relationship between the older age group and higher team category, increasing the possibility of injury, as shown in other studies (8). In younger ages, there is a higher degree of emphasis on the development of preventive measures, such as the adequate observance of footballing rules and fair play, to reduce injury levels and to promote safe footballing, for children and teenagers (3).

In respect to junior footballers, several studies have demonstrated an increased injury incidence in amateur players, compared with players from higher categories, which could be due to the lower technical skills, characteristic for amateur players $(3,9)$.

In the present study, one of the influential factors may also be the availability of proper medical assistance for adult and under-19 years old players, where professional medical staff is on hand, during training sessions.

There are several epidemiological studies on file (10, 11), which compare the relationship of age, sex and competitive level, with the risk of injury, and, for this reason, our findings are merely hypothetical and need to be supported with more detailed information.

A higher injury incidence is observed in teams during the period following preseason, in September (preseason, in Spanish football, starting from end of July or beginning of August) and in February, after the Christmas break, when we see an increased level of training in preparation for the second half of the season. The lowest number of visits was in December, coinciding with the period of least activity, due to the Christmas break. Our data show similar findings to other studies, such as that of Brito et al. (10). However, there are also divergences with other studies on the subjects, such as the work carried out by Akkaya et al. (12). In this study, injuries were most prevalent in the months of March, April and May.

With regard to the location of injuries, we observe most injuries occurring to the lower limbs and, predominantly, to the thigh region, followed by common contact areas, adherent to the sport, such as neck, trunk (chest), shoulders and hands, the latter being most typical in goal keepers. Our study coincides with other findings, showing the majority of injuries locate to the lower limbs: muscular distensions, strains and contusions $(6,13)$. Lower limbs are the parts of the body with the highest level of exposure and activity, in football.

The percentage of injuries to the lower limbs, as per our present study, resembles that recorded by other studies, such as those of Hawkins et al. (14) and Akkaya et al. (12). Our data also coincide with studies carried out by Brito et al. (10), Habelt et al. (11) and Mallo et al. (15), the latter showing the thigh region to be the area with the highest proportion of injury, which is in line with the findings of our study.

We observe muscular-related injuries to be the most common, followed by ligament-related and contusions, coinciding with studies carried out by the aforementioned Habelt et al. (11), Brito et al. (10), Price et al. (7) and Junge et al. (16).

The majority of injuries only required one visitto cure, coinciding with similar results in other studies, such as that carried out by Paterson (17). This theory is consistent with other studies and does not warrant limiting participation in the sport, which has widely-known health benefits, in addition to the media value of football, on a social level $(2,3)$.

The most common treatment applied was intramuscular treatment (empowerment, strengthening), a finding in contrast to other studies, showing thermotherapy, as the most preferred (18). These differences may be due to the fact that our study was based on cases treated on the place and not in hospital environment, as was the case in other studies.

Moreover, we observe a significant relationship between training hours (exposure), number of treatments and visits to medical services. As previously mentioned, there are few studies specifically in this regard. However, we can observe similar tendencies in other works, as for example in the case of Peterson et al.(9). As we have noted previously, this could be due to a greater access to medical assistance, by adult players.

This article refers to the etiology of muscle injuries, grouped in to age groups, location and distribution, throughout a season. Although there are similar publications in the literature, who study these variables separately, only few are making a joint analysis of the separate characteristics. This work provides certain amount of de- 
scriptive results, which can serve as a model for future research projects, performing interventions by coaches and medical services of football clubs, to reduce the injuries incidence, especially in the months of greatest physical load and, therefore, improve overall performance. This could provide significant benefits for the health of the players and lead to positive results, for amateur clubs, as in our case, and also for professional clubs, with higher intensity interventions.

In conclusion, the most common pathology in football is represented by injuries of muscular etiology, affecting the lower limbs. Factors such as physical preparation and the level of club professionalism may be influential in preventing these types of injury. In younger players, we observed a lower level of injury, in comparison to adult players, and, therefore, we recommend a greater level of instruction and physical preparation, in early years, as a means of reducing incidences later during adulthood.

\section{Acknowledgments}

Our special acknowledgements go to R.S.D. Santa Isabel for allowing us to work with their different teams.

\section{Footnotes}

Authors' Contribution:All authors agree with the work done and have collaborated actively in its development.

Financial Disclosure:The authors report no conflicts of interest in this work.

Funding/Support:The authors report no fund or support in this work.

\section{References}

1. Licencias de la Real Federación Espa-ola de Fútbol . Available from: http://www.rfef.es/FCKeditor/UserFiles/File/arbitros\%20 abril/triptico_licencias.pdf.

2. Krustrup P, Nielsen JJ, Krustrup BR, Christensen JF, Pedersen $H$, Randers MB, et al. Recreational soccer is an effective health-promoting activity for untrained men. Br J Sports Med. 2009;43(11):825-31. doi: 10.1136/bjsm.2008.053124. [PubMed: 19098116]

3. Koutures CG, Gregory AJ, American Academy of Pediatrics. Council on Sports M, Fitness Injuries in youth soccer. Pediat- rics. 2010;125(2):410-4. doi: 10.1542/peds.2009-3009. [PubMed: 20100755]

4. Kakavelakis KN, Vlazakis S, Vlahakis I, Charissis G. Soccer injuries in childhood. Scand J Med Sci Sports. 2003;13(3):175-8. [PubMed: 12753490]

5. Froholdt A, Olsen OE, Bahr R. Low risk of injuries among children playing organized soccer: a prospective cohort study. Am J Sports Med. 2009;37(6):1155-60. doi: 10.1177/0363546508330132. [PubMed:19279224]

6. Giza E, Micheli LJ. Soccer injuries. Med Sport Sci. 2005;49:140-69. doi:10.1159/000085395. [PubMed:16247265]

7. Price RJ, Hawkins RD, Hulse MA, Hodson A. The Football Association medical research programme: an audit of injuries in academy youth football. BrJ Sports Med. 2004;38(4):466-71. doi: 10.1136/ bjsm.2003.005165. [PubMed:15273188]

8. Vanlommel L, Vanlommel J, Bollars P, Quisquater L, Van Crombrugge $\mathrm{K}$, Corten $\mathrm{K}$, et al. Incidence and risk factors of lower leg fractures in Belgian soccer players. Injury. 2013;44(12):1847-50. doi:10.1016/j.injury.2013.07.002. [PubMed: 23916900]

9. Peterson L, Junge A, Chomiak J, Graf-Baumann T, Dvorak J. Incidence of football injuries and complaints in different age groups and skill-level groups. Am J Sports Med. 2000;28(5 Suppl):S51-7. [PubMed:11032108]

10. Brito J, Malina RM, Seabra A, Massada JL, Soares JM, Krustrup P, et al. Injuries in Portuguese youth soccer players during training and match play.J Athl Train. 2012;47(2):191-7. [PubMed: 22488285]

11. Habelt S, Hasler CC, Steinbruck K, Majewski M. Sport injuries in adolescents. Orthop Rev (Pavia). 2011;3(2):e18. doi: 10.4081/or.2011. e18. [PubMed: 22355484]

12. Akkaya S, Serinken M, Akkaya N, Turkcuer I, Uyanik E. Football injuries on synthetic turf fields. Eklem Hastalik Cerrahisi. 2011;22(3):155-9. [PubMed: 22085351]

13. Junge A, Dvorak J. Soccer injuries: a review on incidence and prevention. Sports Med. 2004;34(13):929-38. [PubMed:15487905]

14. Hawkins RD, Hulse MA, Wilkinson C, Hodson A, Gibson M. The association football medical research programme: an audit of injuries in professional football. Br J Sports Med. 2001;35(1):43-7. [PubMed:11157461]

15. Mallo J, Gonzalez P, Veiga S, Navarro E. Injury incidence in a spanish sub-elite professional football team: a prospective study during four consecutive seasons. J Sports Sci Med. 2011;10(4):731-6. [PubMed: 24149566]

16. Junge A, Cheung K, Edwards T, Dvorak J. Injuries in youth amateur soccer and rugby players--comparison of incidence and characteristics. Br J Sports Med. 2004;38(2):168-72. [PubMed: 15039253]

17. Paterson A. Soccer injuries in children. Pediatr Radiol. 2009;39(12):1286-98. doi: 10.1007/s00247-009-1416-1. [PubMed: 19847416]

18. van Beijsterveldt AM, Steffen K, Stubbe JH, Frederiks JE, van de Port IGL, Backx FJG. Soccer injuries and recovery in Dutch male amateur soccer players: results of a prospective cohort study. Clin J Sport Med. 2014;24(4):337-42. [PubMed: 24346734] 